\title{
Development of "Sponge" in Sponge City Construction
}

\author{
Jiawei Cai, Zhenfei Zhang \\ Nanyang Institute of Technology, Nanyang, 473000, China
}

Keywords: Sponge city, Sponge, Low-impact development

\begin{abstract}
Sponge city is a new type of urbanization development model which can effectively solve the urban water security problems and promote the harmonious development of man and nature. The development of "sponge" plays an important role in the construction of sponge city. In this paper, the basic methods of protection, restore and construction of "sponge" development are expounded in details, and the experiences of "sponge" development in Tianjin, Hangzhou and Chongqing are demonstrated to provide some references for the relative researchers.
\end{abstract}

\section{Introduction}

With the continuous expansion of the scale of city construction, hardening floor and road square were increased, the rainwater most rely on the municipal pipe network, but when the city network encountered rain heavy rainfall, many city domestic severe waterlogging, resulting in life and property in the disaster. Sponge city refers to the city can be like a sponge to adapt to changes in the environment and respond to natural disasters and other aspects of good flexibility". The essence of sponge city is to change the concept of traditional urban construction and realize the coordinated development of resources and environment. When successful industrial civilization reached the peak, people used to overcome nature, transcend nature and transform nature, resulting in serious urban diseases and ecological crisis. The sponge city follows a low impact development model that conforms to nature and is in harmony with nature. Traditional cities use land for high intensity development. Sponge cities realize the harmonious coexistence of man and nature, land use, water environment and water cycle. Traditional urban development methods change the original water ecology, while sponge cities protect the original water ecology. The traditional city construction model is extensive, sponge city on the surrounding water ecological environment is low impact. After the traditional city was built, the surface runoff increased a lot, and the surface runoff remained unchanged after the sponge city was built. At present, the phenomenon of insufficient cavernous body is widespread throughout the country. The decrease of public green space and the increase of hard ground lead to the serious shortage of green sponge which can absorb water, so that the construction of sponge city in our country lacks the basic strength. Domestic "sponge" development and sponge city construction will be a long-term exploration and growth stage.

\section{Development Models of "Sponge"}

Protection of "Sponge". Compared with the construction of artificial sponge, the protection of sponge bodies such as natural rivers, lakes or wetlands has the advantages of no manpower and material consumption, simple and convenient. The original "sponge" is in the city include inside and around the region, rivers, lakes, rivers, ponds, wetlands, forests and swamps, the original "sponge" flood ability and strong self-repair ability in artificial sponge". The current scope of human activities is increasing, natural sponge is less and less, therefore, should be set in the limited area of city planning, set up the park in the inner city, periphery nature reserve, in the protection of natural sponge is spoilt by human activities at the same time, give full play to their landscape value and aesthetic value. From the point of view of city development, city construction and development of the early in rivers, gathered in the river basin near the river basin land has a relatively long history of 
development and utilization, in the land development process in the long time, farming and land use structure of the disorder are all human the activities of the obvious effect on the river water environment, rivers are fragile ecological environment. The vulnerability of the ecological environment of the river will be directly reflected in the artificial lake area of terrestrial plants and aquatic organism damage, aquatic organisms, particularly fish resources of the natural proliferation was severely affected, balanced development will ultimately be a serious threat to the ecological environment. The water environment protection of urban rivers and artificial lakes should begin with ecological greening. We consider the seasonal and ornamental nature of green vegetation, so as to achieve the unity of ecological protection and urban beautification. Relevant government departments and staff need to implement the construction of widening the river and increasing the depth of the river as soon as possible, contributing to the development of the city's cavernous body.

Restore of "Sponge". Under the traditional extensive urban construction mode, the urban green space, water body and wetland have been destroyed, so that they can be restored and repaired gradually by means of physical, biological and ecological techniques. Polluted water bodies and land not only do not have the ability to save and regulate rainwater, but also have a negative impact on the lives and health of the people around them. Many media have published reports of frequent pollution of nearby resident's due to water pollution problems. Therefore, it is urgent to repair and restore the damaged cavernous body. There are many methods for the repair of sponge body. The most common methods are physical sieve filtration, sewage interception, dredging and biological ecological restoration. The physical filtration control of pollutants from the source, improve the sewage pipe network system and city garbage removal system, and through the combination of mechanical and hydraulic erosion of two kinds of means, in the drought period and flood period of pollutants in rivers of silt cleaning, removal of point and non-point source pollution. Biological and ecological restoration technology is a new type of environmental biological technology developed in recent years, mainly the use of microorganisms, plants and other biological life activities, transfer, transformation and degradation of pollutants in water. We need to recognize that the current society in river water coverage area shrinking, relying on the city river and the formation of the artificial lake as the municipal engineering construction projects in the development of "sponge" the most effective water conservancy construction project. However, the serious deterioration of the water environment in the industrialization and modernization of this artificial lake has become increasingly prominent, and seriously affected the ecological water system of the whole city, so it is urgent for the relevant staff to deal with and improve it. We should strictly control the use of pesticides and fertilizers in the farming process of crops along the upper reaches of the lake. We should also set up a corresponding water cut and drainage network between the lake district and the river to avoid the lake surface erosion and pollute the water body.

Construction of "Sponge". In the process of urban development and construction, we should rationally control the development intensity and reduce the damage to the original urban water ecological environment. Keep the ecological land, rivers and lakes proper excavation ditch, increase water area. From the beginning of architectural design, roof greening, permeable pavement, constructed wetlands and so on are adopted to promote rainwater storage and purification. This will be from the planning point of view, increase the green land area, and truly from the amount of water to ensure that sponge water, spit water smoothly, not just rely on the effect of limited technology. The main ways to increase the urban greening are to construct the country park, the small green space and the small park, and build a complete urban green water permeable network. In the low impact development and the construction of the grey infrastructure, we pay attention to the excavation and supply of the cavernous body, and the green infrastructure itself is another form of expression of "sponge". Through the planning and reconstruction of the used land resources, a simple, low-cost and efficient facility can be built to save land and solve the problem of rainwater circulation and utilization. The low impact development and green infrastructure work, not only can effectively solve the city waterlogging, the rain quickly away from the road surface, but also can complement the conservation of groundwater resources, groundwater is rich in content, to solve the problem of insufficient groundwater dry winter period, is a very effective city "sponge" reserve resources 
development and construction method. Through the rain garden, grass ditch and sunken lawn, and the green roof, improve green rainwater retention and infiltration capacity. Vigorously promote permeable pavement, as far as possible more buildings, outdoor ground, roads, squares and parking spaces can be converted to permeable surface, so that rainwater infiltration, recharge groundwater. Rainwater passes through these "sponge", infiltration, stagnant storage, purification, reuse, and finally the remaining part of the platoon.

\section{"Sponge" Development Experiences in Different Cities in China}

"Sponge" Development Experiences of Tianjin City. In recent years, due to rapid urban construction, some wetlands have been buried or polluted in Tianjin. Therefore, the proposition of sponge city also puts forward new requirements for the protection and development of "urban water" in Tianjin. Before the construction of the site, the abandoned shooting range was low, full of garbage, seriously polluted and salinization of land. With the construction of Tianjin expressway system, the development of the surrounding areas has been promoted. To improve the regional environment, 2003, the Tianjin municipal government has started the construction of the bridge park. The characteristics of the project based on the requirements of Bridge Park, retain some ponds, waters, and put forward to park a rainwater collecting and purifying effect, requirements of saline alkali land was improved, and the garbage in the local ecological treatment site. Landscape design above requirements, the proposed landscape regeneration strategy. Combined with the original water area topography, we designed the inverted cone concave green space and the "blister", that is, we have been put forward the "small sponge."". The "bubble" is a forest Wai, each "bubble" has different elevation, elevation difference is designed to show the characteristics of biological communities in different regions of Tianjin. The initial community is the land taken from different altitude and soil characteristics in Tianjin. A complete sampling method is adopted to ensure the self-repair capacity of the original habitat without damaging the original habitat. And no pollution in the site is combined with the topography of the landfill. At the same time, using red plank road and viewing platform system, each wetland blister relates to each other to form a unique wetland landscape and rainwater collection demonstration area. At the same time, the park also combines the natural landscape with the Tianjin culture, and utilizes the native plants and local materials of Tianjin to reflect the water culture and industrial culture.

"Sponge" Development Experiences of Hangzhou City. Hangzhou introduced the concept of "low impact development" at the beginning of planning and design, and maintain the original hydrological function as far as possible after the site development, and improve the infiltration capacity of the soil. At the same time, we should pay attention to the pollution of the surface runoff caused by the initial rainfall, and control the focus of the planning and design from the simple rain water control to the quantity of water and the quality of water. In the development of scientific delineation of the city boundary, influence should be to maximize the protection of the rivers, lakes, wetlands, ditches and other "sponge" from development activities, and as far as possible the use of physical, biological and ecological techniques, the destruction of green, water, such as wet sponge gradually restored and repair. For city roads, green land, rivers and lakes of different types of features, give priority to the infiltration, storage, purification and other "sponge" function of the rainwater control facilities, the peak flow of storm water runoff temporary pool, when the runoff peak after the fall, then the water will be discharged from the pond slowly. The waters of the river to protect the city should be in accordance with the upstream catchment area or total annual runoff, the river level construction, clear planning channels and different sections of the function, classification, to determine the local plane pattern of main river, river, general River, river water holding rate. And the river water ecological environment can be maintained and improved. The natural form of river course should be preserved in the layout of river course, and the engineering measures to influence the natural form of river channel should be avoided, and the occupied water area should be recovered according to the principle of fill and fill balance. 
"Sponge" Development Experiences of Chongqing City. Chongqing is in the upper reaches of the Yangtze River in the southwest of China, and is a typical mountain city. The topography of this area is dominant, and the soil water storage layer is thin, so it is not suitable for water storage. With the acceleration of urbanization, the proportion of hardened urban pavement is increasing, which leads to the rapid increase of impervious surface. The dual effects of natural topography and human factors lead to rapid convergence of rainwater, and rainwater needs to be pumped into the storm water network in a short period of time, resulting in heavier load of the drainage network. Control technology of non-point source pollution in super fine sand source area, adding soil polymer to increase the viscosity of super fine sand, avoid soil erosion, improve soil water seepage ability and reduce surface runoff. Under complex geological conditions, park penetration reduction technology, the city hardened ground around the green grass ditch, construction and other facilities, the penetration and hysteresis of runoff, runoff pollution control. Large slope runoff infiltration technology for road shoulder, mountain city terrain slope characteristics, by setting the cascade drains, slows down the velocity of flow, surface runoff pollution and undertake the collection, treatment and discharge function. Modular large slope runoff control filter system. Using the sand layer at the bottom of the filter, the rainwater was classified and filtered to deal with the heavy polluted runoff in the early stage of rainfall. The runoff is enhanced by the lateral flow biofilter, and a multistage runoff filtration treatment system integrating precipitation, filtration, adsorption and biological transformation is used to purify the rainwater.

\section{Conclusion}

The development of "sponge" is the most important part of the construction of sponge city. The key tasks of the development mainly include the protection, reparation and construction. The connotations of "sponge" and sponge city are still developing. Building a sponge city theory with Chinese characteristics and carrying out scientific practice is a long way to go.

\section{Acknowledgements}

Soft Science Research Project of National Level of the Ministry of Housing and Urban-Rural Development (Grant No. K42016218) named "Research and Demonstration of Integration Technology and Models of 'Internet-Sponge City"'.

\section{References}

[1] Tong He, Wang Jianlong, Che Wu, Li Junqi, Nie Aihua. The Methodological Discussion on Urban Planning on the Concept of Sponge City [J]. South Architecture, 2015(4): 108-114.

[2] Yu Jianmin, Zhou Jingzeng, Ke Hexin, Wang Weidong. Exploration on Model of the Spongy Body City Construction and Exploitation for Hangzhou [J]. Zhejiang Construction, 2015, 32(10): 51-53.

[3] Han Xu, Zhao Yaqian. "Sponge” Developmentin Sponge City Construction [J]. Journal of Earth Sciences and Environment, 2016, 38(5): 708-714.

[4] Wu Danjie, Zhan Shengze, Li Youhua, Tu Manzhang, Zheng Jianyang, Guo Yingyuan, Peng Haiyang. New Trends and Practical Research on the Sponge Cities with Chinese Characteristics [J]. China Soft Science, 2016(1): 79-97. 